\title{
Characteristics of Short-Period Internal Waves in the Avacha Bay Based on the In Situ and Satellite Observations in August-September, 2018
}

\author{
E. I. Svergun 1, 2, *, A. V. Zimin 1, 2 \\ ${ }^{1}$ Shirshov Institute of Oceanology, Russian Academy of Sciences, Moscow, Russian Federation \\ ${ }^{2}$ Saint-Petersburg State University, Saint-Petersburg, Russian Federation \\ *Egor-svergun@yandex.ru
}

Purpose. The paper is aimed at evaluating the characteristics of short-period internal waves in different regions of the Avacha Bay in the Pacific Ocean concerning their hydrological and morphometric conditions.

Methods and Results. The characteristics of internal waves are assessed through synthesizing the results of the in situ studies in the Avacha Bay in August-September, 2018, the high-resolution remote sensing data and the results of tidal modeling. The data of the in situ and satellite observations of internal waves were also directly compared. The results show that in the shallow part of the Avacha Bay, the waves, whose heights are from 10 to $15 \mathrm{~m}$ were observed. They constitute $10 \%$ of the total number of cases. In the deep-water part of the bay, the internal waves are also often observed, but their maximum height does not exceed $10 \mathrm{~m}$. The satellite images show 72 manifestations of short-period internal waves. Some of them spread to the coast with a tidal frequency from the generation source located around the $500 \mathrm{~m}$ isobath where the bottom abruptly slows down. Conclusions. The results of the investigation revealed a pronounced relationship between the wave trains recorded in the shallow-water area and the semidiurnal tidal dynamics. Analysis of the hydrological situation and the satellite images permitted to assume that the internal waves could be generated as a result of not only a barotropic tide collapse, but also due to the inertial oscillations of the frontal zone formed by the Kamchatka current meanders in the presence of a shallow sharpened pycnocline. Having been analyzed, the synchronous satellite and in situ observations made it possible to find out that the internal waves of the 5-8 m height were distinctly manifested on the sea surface in case the pycnocline depth was $10-20 \mathrm{~m}$.

Keywords: intensive internal waves, expedition observations, satellite images, phase velocity, tidal currents.

Acknowledgements: the results of expedition research were processed within the framework of the state tasks No. 0149-2019-0015 "Wave processes, transport phenomena and biogeochemical cycles in the seas and oceans: investigation of forming mechanisms on the basis of physical and mathematical modeling and field experiments”. The results of satellite observations were processed within the framework of the RFBR grant No. 18-35-20078 mol_a_ved. The authors are grateful to N.V. Sandalyuk, the research engineer at Saint Petersburg State University, for his assistance in selecting the operational modeling data, as well as to N.N. Shpilev and D.I. Dudko, the engineers of the Krylov State Research Center, for their participation in the expedition studies.

For citation: Svergun, E.I. and Zimin, A.V., 2020. Characteristics of Short-Period Internal Waves in the Avacha Bay Based on the In Situ and Satellite Observations in August-September, 2018. Physical Oceanography, [e-journal] 27(3), pp. 278-289. doi:10.22449/1573-160X-2020-3-278-289

DOI: 10.22449/1573-160X-2020-3-278-289

(C) E. I. Svergun, A. V. Zimin, 2020

(C) Physical Oceanography, 2020

\section{Introduction}

The World ocean continental margins are characterized by increased intensity of internal waves. Due to the nonlinear transformation of internal tides, short-period internal waves (SIWs) can be formed there. They are featured by periods from units of 
minutes to tens of minutes and wavelengths from hundreds of meters to units of kilometers [1]. Such waves are most often recorded in the seasonal thermocline area and belong to the lowest mode vibrations. SIWs are often intense: are more than $10 \mathrm{~m}$ in height and are characterized by significant non-linearity [2]. Their manifestations are variable over time. Among these waves, trains of considerable height, having a great effect on the propagation of sound and the mixing of waters, are noted[3].

The Pacific Ocean margins near the Kamchatka Peninsula are characterized by a small shelf width, a strong bottom slope and a complex hydrological structure of waters formed under the Kamchatka Current influence [4]. Another feature of this water area is also internal waves, the manifestations of which on the sea surface are recorded by remote sensing methods $[5,6]$. A generalization of satellite and contact observations revealed a complex picture of SIWs interacting with each other and with the meanders of the Kamchatka Current near the Kamchatka Peninsula ocean coast [1]. It was found that intense internal waves (IIW) with a tidal frequency of 10-15 $\mathrm{m}$ in height are a typical phenomenon both for the peninsula shelf and for adjacent sections of the continental slope $[1,7]$.

However, due to the region isolation and the frequent adverse hydrometeorological conditions, the data on the statistical characteristics of SIWs in various depth sections of the Kamchatka ocean coast is very poor. It is limited by the results of synchronous aviation and ship observations carried out only in the Kronotsky Gulf. Although in the Avacha Bay, the manifestations of internal waves are also regularly recorded by satellite data [6].

An attempt to fill this gap was made on the basis of a summary of the results of in situ studies carried out in the summer - autumn of 2018 in the Avacha Bay, supplemented by high-resolution remote sensing data from the latest Sentinel satellites of the European Space Agency (ESA), as well as by Copernicus service simulation results.

Hence, the present paper is aimed at describing the statistical characteristics and geographical features of the distribution of SIWs in the Avacha Bay of the Pacific Ocean according to data of the mixed observations.

\section{Description of the Measurement Data and its Processing Methods}

Contact observations. In situ measurements were carried out in the Avacha Bay of the Pacific Ocean in August-September 2018 at a polygon above the mainland slope near the Cape Shipunsky, characterized by depths from 100 to $200 \mathrm{~m}$ (shallow-water polygon), and also far off to sea - at a polygon above the slope of the Kuril-Kamchatka Trench, where the depths exceed $1000 \mathrm{~m}$ (deepsea polygon). The position of the measurement polygons is shown in Fig. 1, $a$.

Measurements were taken from a set adrift vessel. A bunch of 26 PME (Great Britain) temperature sensors with a distance between the sensors of $2 \mathrm{~m}$ and a total length of $50 \mathrm{~m}$ was used for measurements. The sensors recorded the temperature with an accuracy of $\pm 0.05^{\circ} \mathrm{C}$. The position of the lower end of the bunch was monitored using a pressure sensor. Before the start of each measurement episode, from the carrier vessel the CTD probing was carried out with an SBE 25 instrument (USA) to determine the transient layer depth. Based on the results of such probing, the position of the sensor bunch along the vertical was corrected. The total duration 
of the measurements at the shallow-water polygon was 44 hours, at the deep water one -97 hours. Moreover, each measurement episode lasted from 6 to 18 hours.
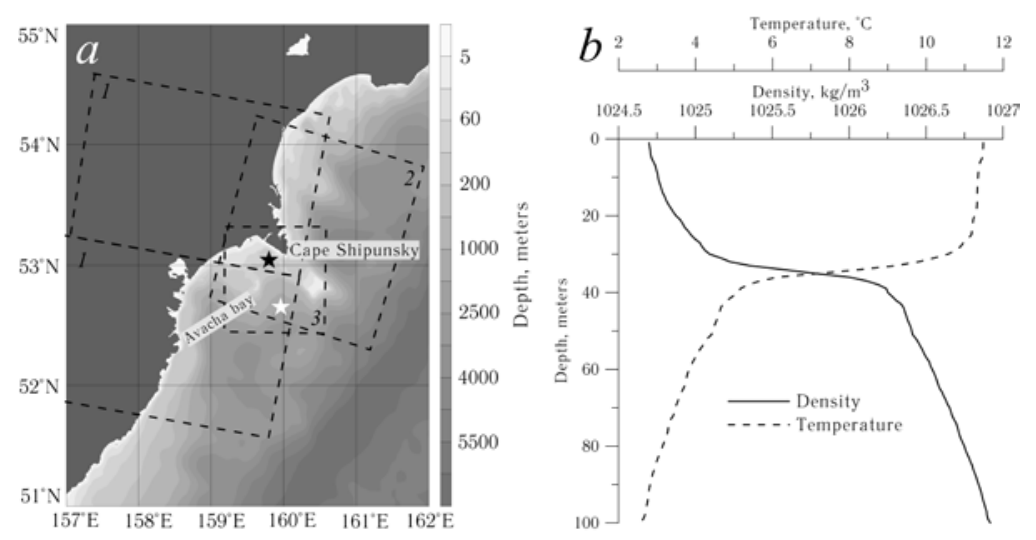

F i g. 1. Position of the polygons of in situ measurements and coverage of the Avacha Bay water area with satellite images (a) (black star shows the shallow polygon, white star - the deep-sea polygon, dotted frame - the borders of satellite images: 1 - Sentinel-1A on August, 13 and 24, and September 17, 2018; 2 - Landsat-8 on August 22, and September 16 and 23, 2018; 3 - Sentinel-2A and Sentinel-2B on August, 23, and September 12 and 27, 2018); temperature and density vertical profiles at the polygon near the Cape Shipunsky based on the CTD-sensing on September 27, $2018(b)$

It should be specified that according to CTD probing it was established that at the polygons the positions of the thermocline and pycnocline coincided (Fig. 1, b). This permits to estimate the height and period of each internal wave, using only records of temperature fluctuations obtained from a bunch of temperature sensors. According to these observations, periods and heights of internal waves were estimated using the technique described in detail in [8].

To compare the moments of registration of the trains of SIWs with tidal currents, the data of the assimilation product The Mercator global ocean operational analysis system (URL: http://marine.copernicus.eu/servicesportfolio/access-to-products) containing the value of the hourly horizontal components of the tidal currents at a point corresponding to the shallow-water polygon position. Operative simulation data is provided by the Copernicus service.

Satellite observations. To analyze the characteristics of surface manifestations of SIWs, the data of Sentinel-2A and Sentinel-2B spectroradiometers in the optical range with a spatial resolution of $10 \mathrm{~m}$ from August 23, September 12 and 27, 2018; Landsat-8 spectroradiometer images in the optical range with a resolution of $30 \mathrm{~m}$ from August 22, September 16 and 23, 2018; images of Sentinel-1A synthetic aperture radar in the C-band with VVpolarization and IW shooting mode with a resolution of $20 \mathrm{~m}$ (URL: https://sentinel.esa.int/web/sentinel/missions/sentinel-1) from August 13 and 24, September 17, 2018, was used. Totally, nine satellite images were used in the work. The coverage of the Avacha Bay area by satellite images is shown in Fig. 1, $a$. 
Internal waves on the sea surface in radar images appear in the form of alternating arched light and dark stripes forming wave packets. This phenomenon is caused by various characteristics of the radar signal reflection by capillary surface waves modulated by the current that occurs during the passage of the SIWs $[9,10]$. The following characteristics as the position of the manifestation, wavelength, arc length of the leading crest in the packet, propagation direction and the number of waves in the packet are determined for each surface manifestation of internal waves (IW).

To estimate the relationship between the internal waves observed and their surface manifestations, a direct comparison of contact and satellite observations was carried out on September 28, 2018.

Description of the hydrological situation at the polygons during the in situ measurements. During the analysis of CTD probing data, long-term variations of the pycnocline position that occurred during the in situ observations were revealed. Fig. 2, $a$ and 2, $b$ show the vertical density profiles obtained at different time at the polygons.
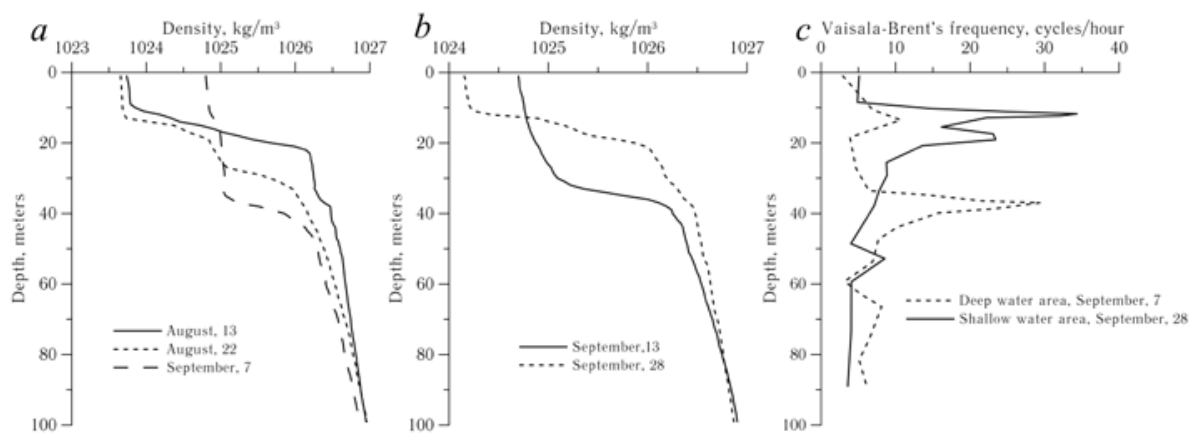

F i g. 2. Profiles of vertical distribution of hydrological characteristics: $a$ - density at the deep-sea polygon; $b$ - density at the shallow-water polygon; $c$-Väisälä - Brent frequency at the deep-sea and shallow-water polygons

Fig. 2, a shows that during in situ observations at a deep-sea polygon, the pycnocline deepened, the upper mixed layer thickness increased and the pycnocline density decreased. At the beginning of the in situ works, the pycnocline was located at a depth of 10 to $20 \mathrm{~m}$ at the deep-sea polygon; the density gradient in the pycnocline was 0.26 c.u./m, the upper mixed layer thickness was $10 \mathrm{~m}$. When the works at the deep-sea polygon terminated, the pycnocline was at depths from 40 to $50 \mathrm{~m}$, the density gradient in it was 0.12 c.u./m and the upper layer thickness was $40 \mathrm{~m}$. Fig. 2, b, on the contrary, shows that during the in situ observations, a pycnocline at shallow water polygon increased. Thus, at the beginning of the works, the pycnocline was in the layer from 5 to $45 \mathrm{~m}$, the density gradient in the pycnocline was $0.08 \mathrm{c} . \mathrm{u} . / \mathrm{m}$, and the upper layer thickness was only $5 \mathrm{~m}$. When the works at the shallow water polygon were finished, the pycnocline was in the layer from 10 to $20 \mathrm{~m}$, the density gradient in the pycnocline was $0.18 \mathrm{c.u} . / \mathrm{m}$, and the upper mixed layer thickness was $10 \mathrm{~m}$. The considered evolution of the vertical temperature profiles at PHYSICAL OCEANOGRAPHY VOL. 27 ISS. 3 (2020) 
the shallow and deep-sea polygons was apparently due to the combined action of storm surface waves and mesoscale meanders of the Kamchatka current recorded in the optical range in satellite images (Fig. 3).

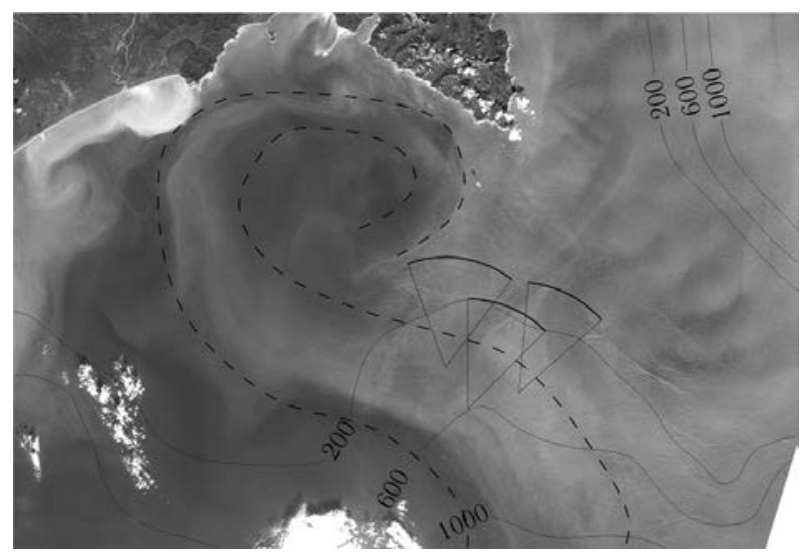

F i g. 3. Example of recording the Kamchatka current meanders on the Landsat-8 satellite image on August 22, 2018 (dashed lines on the images indicate position of the fronts based on the surface manifestations, solid thick lines - manifestations of the short-period internal waves (SIWs), solid thin lines - the assumed places of SIWs generation)

Fig. 2, c shows vertical profiles of the Väisälä - Brent frequency at the time of work termination in shallow and deep-sea polygons. It can be seen that in the shallow water polygon, the layer of increased values of the Väisälä - Brent frequency extends at depths from 10 to $30 \mathrm{~m}$, and in the deep-sea one - from 30 to $50 \mathrm{~m}$. The maximum Väisälä - Brent frequency value in the shallow water polygon is greater than in the deep-sea one.

SIWs characteristics according to the data of contact observations: analysis and discussions of the results. Based on the processing results of records of temperature fluctuations (Fig. 4), primary statistics of the wave characteristics were obtained, and the frequency repeatability estimates of the SIWs heights presented in the table were made.

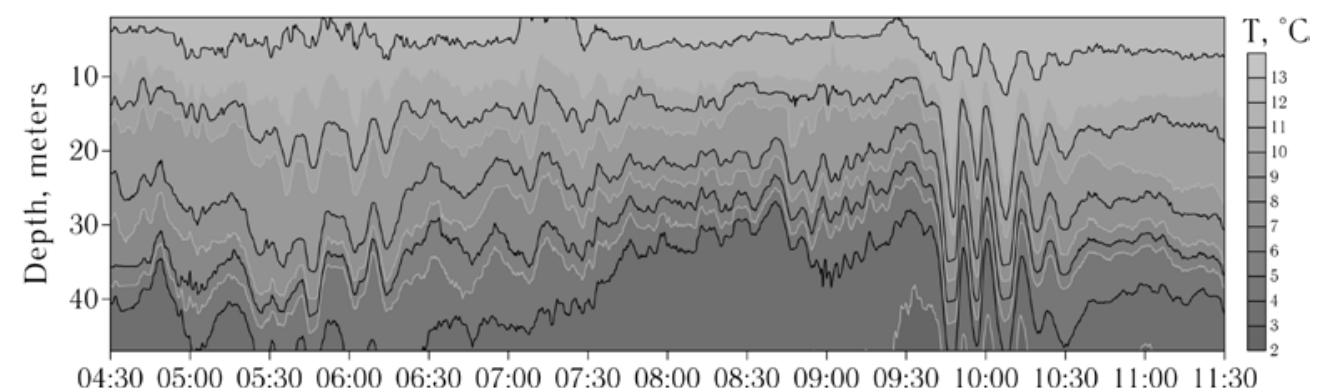

F i g. 4. Example of the records of temperature fluctuations from the $P M E$ thermistor chain measurements at the shallow-water polygon on September 16, 2018 
Repeatability of the short-period internal wave heights at the deep-sea and shallow-water polygons

\begin{tabular}{c|cc}
\hline \multirow{2}{*}{ Height, m } & \multicolumn{2}{|c}{ Repeatability, cases } \\
\cline { 2 - 3 } & Deep-sea polygon & Shallow-water polygon \\
\hline $2 \div 3$ & 179 & 84 \\
$3 \div 4$ & 97 & 38 \\
$4 \div 5$ & 54 & 20 \\
$5 \div 6$ & 33 & 12 \\
$6 \div 7$ & 19 & 7 \\
$7 \div 8$ & 15 & 7 \\
$8 \div 9$ & 7 & 3 \\
$9 \div 10$ & 1 & 1 \\
$10 \div 11$ & - & - \\
$11 \div 12$ & - & 1 \\
$12 \div 13$ & - & 2 \\
$13 \div 14$ & - & - \\
$14 \div 15$ & - & 1 \\
$15 \div 16$ & - & 177 \\
\hline
\end{tabular}

Totally, 582 fluctuations were detected on temperature records, 405of which were in the deep-sea area, and 177 - in the shallow-water one. This significant difference is due to the fact that the duration of measurements in areas is very different. However, if the number of waves at the time of recording is normalized, then the frequency of recording internal waves in both the deep-sea and shallow water areas is about four waves per hour. Differences in the statistical characteristics of the periods of waves recorded in different regions are insignificant: waves have an average period of about 10 minutes.

The other picture is observed when analyzing the primary statistics of wave heights: when the average values are equal, the maximum recorded wave heights at the polygons vary greatly - in the deep-sea region the maximum wave height is $9 \mathrm{~m}$, and in the shallow-water region - $15 \mathrm{~m}$. In shallow-water area, repeatability of IIW with heights from 10 to $15 \mathrm{~m}$ reaches $6 \%$ of the total number of waves, while SIWs with a height of $15 \mathrm{~m}$ are recorded twice during the observation period. In the deep-sea area, strongly nonlinear waves with a height of 9 to $10 \mathrm{~m}$ (for brevity such waves will be called near-intense ones) are recorded in $1 \%$ of cases. The highest repeatability in the areas have waves having height of 2 to $3 \mathrm{~m}$.

The significant difference in the SIWs characteristics in the deep-sea and shallow water polygons can be explained by the previously described differences not only in the bottom topography of the studied areas, but also in the hydrological situation. Hydrological features, along with a strong bottom slope and meanders of the Kamchatka Current, interacting with the pycnocline, create more favorable conditions for the generation of IIW trains in a shallow water polygon. For the White and Black Seas, for example, it is known [12, 13] that SIWs of considerable height are generated under conditions of a shallow-lying thermocline with elevated temperature gradients when it interacts with meandering fronts. 


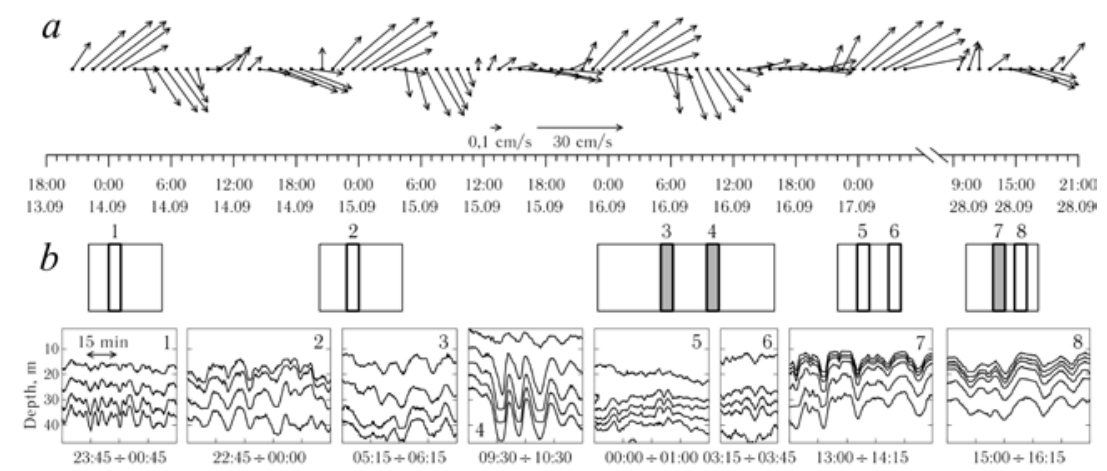

F i g. 5. Comparison of the records of temperature fluctuations of the shallow-water polygon and the tidal currents from September 13 to 28, 2018: $a$ - graph of module and direction of the tidal currents; $b$ - temporal frameworks of the temperature fluctuations records (above) and their fragments illustrating the trains of distinctly pronounced and intense SIWs (below). Thin frames show the records of temperature fluctuations (the time axis coincides with the chart of tidal currents), bold frames $(1,2,5,6,8)$ - the moments of recording the SIWs trains, bold frames with grey fill $(3,4,7)$ the moments of recording the intense internal wave trains

Fig. 5 presents a comparison of the records of intense and near-intense SIW trains with model values of the velocity and direction of tidal currents at a point closest to the points of a shallow water polygon, according to The Mercator global ocean operational analysis system data.

Fig. 5 shows that near-intense waves and IIW are recorded at the moments when the module of tidal currents is close to maximum, while tidal currents are directed perpendicular to the coast, either toward or away from it. I.e., the SIW trains are recorded both at high tide and low tide. An analysis of temperature records showed that IIW and near-intense waves are recorded with a frequency of 5-7 hours, which coincides with the results of earlier studies carried out here [7]. An example is the record of September 16 (see Fig. 4), on which IIW are recorded with a frequency of about 5 hours.

The SIW characteristics according to the satellite data. Comparison of the SIW characteristics according to the contact and satellite data. For a total, 72 surface manifestations of SIW packets with a wavelength of 200 to $800 \mathrm{~m}$ in the packet at an average wavelength of $400 \mathrm{~m}$ were recorded at 9 radar images. The leading crest length in the IIW packet varies from 4 to $39 \mathrm{~km}$, averaging $14 \mathrm{~km}$. The number of waves in the package varies from 2 to 10 . Knowing the characteristics of surface manifestations, the area of the water area occupied by them can be approximately estimated. It is calculated as the product of the leading manifestation crest length, the wavelength and the number of waves in the packet. It amounted to $\sim 1700 \mathrm{~km}^{2}$. Considering that the approximate Avacha Bay area is $4,800 \mathrm{~km}^{2}$, it can be said that the SIW manifestations occupy $35 \%$ of the water area, i.e., they are not local, but ubiquitous. The position of the leading crests of the SIW packet manifestations is shown in Fig. 6, $a$. It can be seen that the largest number of surface SIW manifestations was recorded in the continental slope area at isobaths of 500-1500 m. The vast majority of SIW manifestations are directed to the coast. Since the research in the Avacha Bay water area was carried out under the presence of the Kamchatka Current meanders found in many satellite images analyzed in the optical range (see Fig. 3), it can be assumed that in the shallow 284

PHYSICAL OCEANOGRAPHY VOL. 27 ISS. 3 (2020) 
water area, the SIW generation results from the interaction of a shallow-lying sharpened pycnocline with meanders, and the interaction of tidal currents with bottom irregularities. A small number of surface manifestations were recorded in the $2-3 \mathrm{~km}$ isobath area. The SIW manifestations in the deep-sea area do not have a pronounced tendency in the propagation direction.

Phase velocity of the internal waves from satellite data was determined using the wavelength measured in the image, as well as using data on the vertical density distribution at a point as near as possible to the development location, in accordance with the dispersion relation for internal waves in a two-layer approximation of a stratified medium [14 ]. The wavelength, determined by the distance between adjacent crests of surface manifestations, is $300-400 \mathrm{~m}$. For the indicated wavelengths, the phase velocity is about $0.6 \mathrm{~m} / \mathrm{s}$.

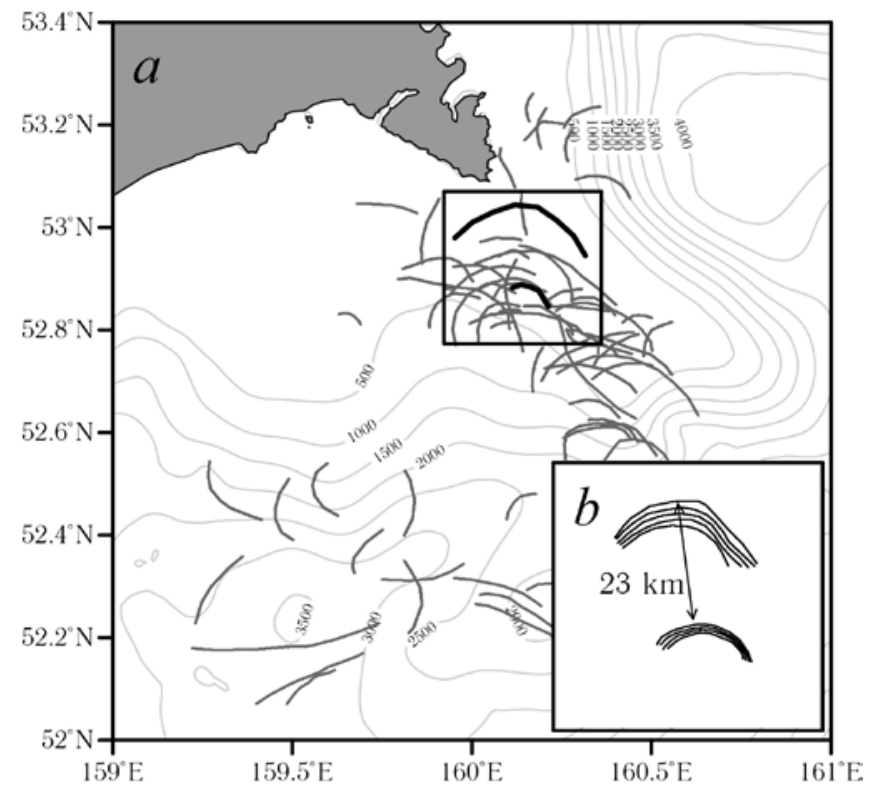

F i g. 6. Surface manifestations of SIWs resulted from analysis of satellite images: $a$-positions of surface manifestations of SIWs at the Avacha Bay water area (grey lines); $b$ - enlarged image of surface manifestations of SIWs propagating with tidal frequency in the marked out area (black lines)

The images contain signatures that regularly propagate in one direction - from the shelf to the coast (Fig. 6, b). If it has assumed that they have a tidal character of generation, then by measuring the distance between the leading crests of the packets in the image and dividing it by the tidal cycle time of 12.4 hours, their phase velocity can be determined. The calculation results showed that the phase velocity of the two recorded manifestations is about $0.6 \mathrm{~m} / \mathrm{s}$, which is close to the previously obtained estimates of the dispersion relation. Their generation source position can be approximately estimated by drawing a normal to the tangents of the leading crest arc at several points (a similar approach was applied in [11]). Geometric constructions in the image, similar to those shown in Fig. 3, showed that the normals drawn to several tangents of the leading crest arc converge in the area near the isobath of $500 \mathrm{~m}$, where the shelf break is located. 
The surface manifestation of the SIWs recorded on the Sentinel-2B satellite image at 10:53 on September 28, 2018 (Fig. 7, a) is in close proximity to the position of the carrier vessel carrying out the contact measurements. The distance from the leading crest of the surface manifestation to the carrier vessel is $7 \mathrm{~km}$. Taking into account its phase velocity, this manifestation will reach the vessel in 4 hours from the moment the satellite received the image, i.e., at about 15:00 on September 28. Fig. 7, $c$ shows a record of temperature fluctuations by a bunch of PME sensors from September 28, 2018.
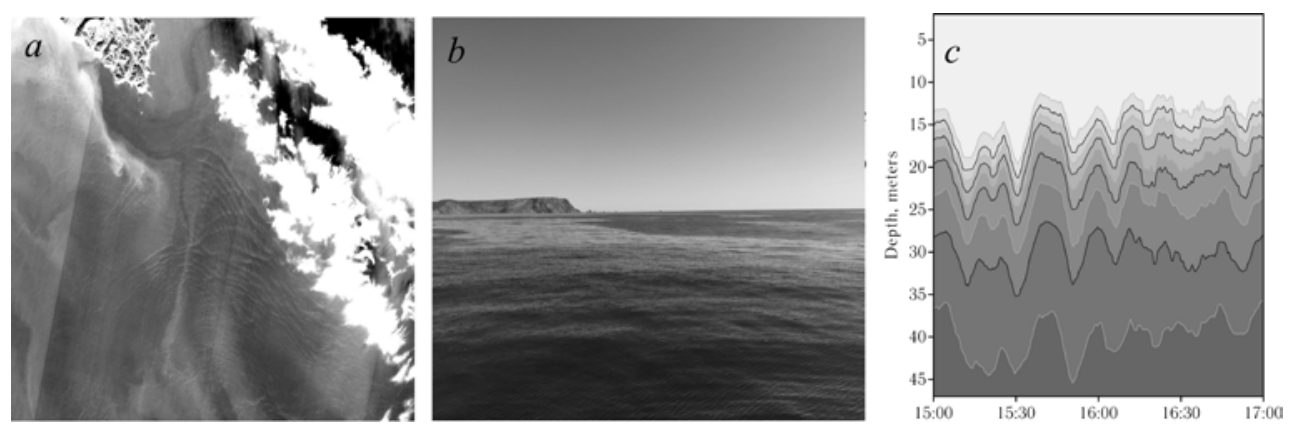

F i g. 7. Comparison of the results of satellite, visual and in situ observations of SIWs: $a$ - fragment of the Sentinel-2B satellite image, 10:53, September 28, 2018; $b$ - photograph of slicks on the Avacha Bay surface, 15: 21, September 28, 2018; $c$ - fragment of temperature fluctuations record, 15:0017:00, September 28, 2018

As can be seen from the figure, in the period from 15:30 to 16:15, i.e., at a moment very close to the estimated time, a pronounced SIW train with heights of $5-8 \mathrm{~m}$ is recorded. Visual observations (Fig. $7, b$ ) also confirm the presence of pronounced slicks at the indicated time on the water area surface, which is a sign indicating the SIW train passage. The phase velocity of this manifestation, determined by contact data, coincides with the results of observations and calculations carried out on the basis of selected sequential packets. Bearing in mind that on the record of temperature fluctuations the wave train was registered at the moment of the highest module of the tidal current (see Fig. 6), then there is no doubt the tidal nature of the detected manifestation generation.

\section{Conclusion}

On the records of temperature fluctuations according to in situ research in the deep-sea and shallow areas of the Avacha Bay, a total of more than 500 internal waves with heights from 2 to $15 \mathrm{~m}$ were recorded. As a result of the analysis of the statistical characteristics of the SIW heights, it was found that in the shallow area of the Avacha Bay in $10 \%$ of IIW cases with heights from 10 to $15 \mathrm{~m}$ are recorded. In the deep sea, they are not recorded. Significant differences in the SIW characteristics in the shelf and deep-sea areas of the Avacha Bay are due to differences in both bottom topography and hydrological conditions, namely: in the shelf area, IIW are formed due to a strong bottom slope, as well as a shallowly sharpened thermocline interacting with the Kamchatka Current meanders. An analysis of the records of temperature fluctuations showed that IIW in the shelf 286

PHYSICAL OCEANOGRAPHY VOL. 27 ISS. 3 (2020) 
zone of the Avacha Bay are recorded in the form of trains of 2-4 waves. A comparison of the records of temperature fluctuations with tidal currents showed a pronounced relationship between the SIW trains and the semidiurnal tidal dynamics.

According to the results of the analysis of satellite images, 72 surface SIW manifestations were found, mainly concentrated in the continental slope area at the $500 \mathrm{~m}$ isobath. In addition, surface manifestations of SIWs propagating with tidal periodicity to the coast were identified. It is shown that SIWs can propagate from the interaction area of a small sharpened pycnocline with Kamchatka Current meanders detected on the satellite images.

Comparison of synchronous data from satellite, contact and visual observations revealed that SIWs with heights of 5-8 m and lengths of 300-400 m have distinct manifestations on the sea surface.

The synthesis of contact and satellite observations made it possible to carry out a qualitative and quite complete spatiotemporal analysis of the variability of the SIW characteristics in the studied area. For the first time, the ubiquitous SIW distribution in the Avacha Bay water area and the regular occurrence of IIWs extending to the coast on the shelf, as well as the connection of the SIW trains with a semidiurnal tidal cycle, are first shown. The features of the SIW field demonstrated within the framework of the present paper are very similar to the results obtained previously for the White Sea [15]. It confirms the conclusion that strong tidal dynamics is a key factor determining phenomena and processes on scales from hundreds of meters to tens of kilometers and the time interval from minutes to half a day.

However, the results obtained raise questions that still have to be answered. Thus, the satellite data analysis shows that in the bay there are SIW signatures with very different spatial scales and orientations, indicating specific conditions for their formation. It is not entirely clear how the variability of hydrophysical fields associated with the Kamchatka Current meanders affects the SIW generation conditions. All this implies further studies, including full-scale ones, in theis area.

\section{REFERENCES}

1. Sabinin, K.D. and Serebryany̌̆, A.N., 2007. "Hot Spots” in the Field of Internal Waves in the Ocean. Acoustical Physics, 53(3), pp. 357-380. doi:10.1134/S1063771007030128

2. Sabinin, K.D., Serebryanyi, A.N. and Nazarov, A.A., 2004. Intensive Internal Waves in the World Ocean. Oceanology, 44(6), pp. 753-758.

3. Rodionov, A.A., Semenov, E.V. and Zimin, A.V., 2012. Advancement of the RealTime Analysis and Forecast Hydrological Sea Fields in Behalf of the Defense and the Conceal of Naval Ships. Fundamentalnaya i Prikladnaya Gidrofizika, 5(2), pp. 89-108 (in Russian).

4. Khrapchenkov, F.F., 1989. Hydrologic Structure and the Distribution of Energy of Eddies in the Kamchatka Current. Meteorologiya i Gidrologiya, (1), pp. 65-71 (in Russian). 
5. Epifanova, A.S., Rybin, A.V., Moiseenko, T.E., Kurkina, O.E., Kurkin, A.A. and Tyugin, D.Yu., 2019. Database of Observations of the Internal Waves in the World Ocean. Physical Oceanography, 26(4), pp. 350-356. doi:10.22449/1573-160X-20194-350-356

6. Jackson, C.R., 2004. An Atlas of Internal Solitary-Like Waves and Their Properties. Alexandria: Global Ocean Associates, 560 p. Available at: https://www.internalwaveatlas.com/Atlas2_index.html [Accessed: 09 June 2020].

7. Pao, H.P. and He, Q., 2002. Generation and Transformation of Intense Internal Waves on Shelves. In: The University of Maryland, 2002. Abstracts for COAA Scientific Workshop, at the University of Maryland, Collage Park, July 13, 2002. Available at: http://www.coaaweb.org/documents/2002JulyAbstracts.pdf [Accessed: 10 June 2020].

8. Zhegulin, G.V., Zimin, A.V. and Rodionov, A.A., 2016. Analysis of the Dispersion Dependence and Vertical Structure of Internal Waves in the White Sea in Experimental Data. Fundamentalnaya i Prikladnaya Gidrofizika, 9(4), pp. 47-59 (in Russian).

9. Robinson, I.S., 2010. Discovering the Ocean from Space: The Unique Applications of Satellite Oceanography. London: Springer, 638 p. doi:10.1007/978-3-540-68322-3

10. Klemas, V., 2012. Remote Sensing of Ocean Internal Waves: An Overview. Journal of Coastal Research, 28(3), pp. 540-546. doi:10.2112/JCOASTRES-D-11-00156.1

11. Zimin, A.V., Romanenkov, D.A., Kozlov, I.E., Chapron, B., Rodionov, A.A., Atadjanova, O.A., Myasoedov, A.G. and Collard, F., 2014. Short-Period Internal Waves in the White Sea: Operational Remote Sensing Experiment in Summer 2012. Issledovanie Zemli iz Kosmosa, (3), pp. 41-55. doi:10.7868/S0205961414030087 (in Russian).

12. Romanenkov, D.A., Zimin, A.V., Rodionov, A.A., Atazhanova, O.A. and Kozlov, I.E., 2016. Variability of Fronts and Features of Mesoscale Water Dynamics in the White Sea. Fundamentalnaya i Prikladnaya Gidrofizika, 9(1), pp. 59-72 (in Russian).

13. Ivanov, V.A, Shul'ga, T.Ya, Bagaev, A.V., Medvedeva, A.V., Plastun, T.V., Verzhevskaia, L.V. and Svishcheva, I.A., 2019. Internal Waves on the Black Sea Shelf near the Heracles Peninsula: Modeling and Observation. Physical Oceanography, 26(4), pp. 288-304. doi:10.22449/1573-160X-2019-4-288-304

14. Konyaev, K.V. and Sabinin, K.D., 1992. [Waves inside the Ocean]. Saint Petersburg: Gidrometeoizdat, 271 p. (in Russian).

15. Zimin, A.V., 2018. Sub-Tidal Processes and Phenomena in the White Sea. Moscow: GEOS, 220 p. (in Russian).

About the authors:

Egor I. Svergun, Senior Research Associate, Shirshov Institute of Oceanology, Russian Academy of Sciences (30, 1ya Liniaya Vasil'evskogo ostrova, St. Petersburg, 119053, Russian Federation), $1^{\text {st }}$ year postgraduate of St. Petersburg State University (7/9, Universitetskaya naberezhnaya, St. Petersburg, 199034, Russian Federation), 
WoS ResearcherID: AAC-7289-2020, Scopus Author ID: 57195066881, egorsvergun@yandex.ru

Aleksey V. Zimin, Head of Laboratory, Shirshov Institute of Oceanology, Russian Academy of Sciences (30, 1ya Liniaya Vasil'evskogo ostrova, St. Petersburg, 119053, Russian Federation), Dr. Sci. (Geogr.), Professor of St. Petersburg State University (7/9, Universitetskaya naberezhnaya, St. Petersburg, 199034, Russian Federation), WoS ResearcherID: C-5885-2014, Scopus Author ID: 55032301400, zimin2@mail.ru

Contribution of the co-authors:

Egor I. Svergun - participation in expedition research, data collection and systematization, preparation of the article text, creation of figures

Alexey V. Zimin - selection and analysis of literature, scientific supervisor, critical analysis and revision of the text

The authors have read and approved the final manuscript.

The authors declare that they have no conflict of interest. 